\title{
EDITORIAL
}

\section{Mast cells: bridging the gap between pre- and post- capillary pulmonary hypertension?}

\author{
D. Montani* and I.M. Lang ${ }^{\#}$
}

$\mathbf{A}$ ccording to the current guidelines for the diagnosis and treatment of pulmonary hypertension $(\mathrm{PH})[1,2]$, the Dana Point diagnostic classification separates precapillary $\mathrm{PH}$, i.e. $\mathrm{PH}$ due to pulmonary vascular disease mainly affecting the pre-capillary arteriolar compartment (i.e. Dana Point groups 1, 3, 4 and 5), from post-capillary disease that originates distal to the capillaries and involves morphological changes in the pre-capillary compartment only occur after a significant pressure increase in the venous compartment (i.e. Dana Point group 2). Currently, a single haemodynamic parameter, i.e. wedge pressure [3], that is commonly flawed by methodological errors [4] is employed to distinguish between pre- and post-capillary disease. This distinction is vital because treatment is completely different for the two classes of disease [2], with a virtual "therapeutic gap" between the two disorders. For example, epoprostenol, the life-saving treatment for pulmonary arterial hypertension (PAH) [5], was shown to be detrimental in congestive heart failure [6].

$\mathrm{PH}$ with left-sided heart disease is classified as a non-PAH form that includes all conditions associated with increased left ventricular filling pressure. A transpulmonary gradient (mean pulmonary arterial pressure $(P$ pa)-pulmonary capillary wedge pressure $(P \mathrm{pcw}))>12 \mathrm{mmHg}$ has been arbitrarily declared as the haemodynamic threshold indicating significant pre-capillary pulmonary vascular disease in left-sided heart disease, and has been classified as "reactive" or "out-of-proportion" $\mathrm{PH}$. By contrast, transpulmonary gradients $\leqslant 12 \mathrm{mmHg}$ have been classified as passive $\mathrm{PH}$, i.e. $\mathrm{PH}$ due to hydrostatic pressure transmitted across the capillary bed of the lung, implying a lack of significant anatomical changes of the precapillary vessels. Naturally, these pressures can be directly changed by relieving left-sided pressures, for example by diuretic treatment, mitral valvulotomy in the case of mitral stenosis, or surgical mitral valve replacement. Whereas mitral stenosis was the most frequent cause decades ago, the most common causes of $\mathrm{PH}$ with left-sided heart disease today are systemic hypertension alone or in combination with metabolic syndrome and ischaemic heart disease, conditions in which $\mathrm{PH}$ develops as a

*Université Paris Sud, AP-HP, Centre de Référence de l'Hypertension Pulmonaire Sévère, Service de Pneumologie et Réanimation Respiratoire, Hôpital Antoine Béclère, INSERM U999, Clamart, France. ${ }^{\#}$ Dept of Internal Medicine II, Division of Cardiology, Medical University of Vienna, Vienna, Austria.

CORRESPONDENCE: I.M. Lang, Dept of Internal Medicine II, Division of Cardiology, Medical University of Vienna, Waehringer Guertel 18-20, 1090 Vienna, Austria. E-mail: irene.lang@ meduniwien.ac.at consequence of compromised left ventricular relaxation and distensibility. An alternative approach, that has been proposed in the past to differentiate between isolated passive transmission of the left-sided filling pressures and concurrent remodelling of the pulmonary venules, may be the incorporation of the diastolic $P$ pa-mean $P$ pcw gradient into the diagnostic work-up of affected patients [7].

Although PH with left-sided heart disease is a common entity [8] associated with an increasing prevalence in the ageing population [9], and long-term follow-up trials have provided strong evidence that $\mathrm{PH}$ in left heart disease carries a worse outcome [10], available data on incidence, pathophysiology and therapy are sparse, and evidence providing firm grounds for haemodynamic classification is lacking. Therefore, basic and clinical work focusing on this important disease entity is needed.

The backward haemodynamic consequences of left-sided heart diseases are thought to progress from venous leakage to lung capillary injury involving impaired $\mathrm{Ca}^{2}+$ signalling and cytoskeletal reorganisation [11], plexiform lesions, arteriolar changes comprising medial hypertrophy, and intimal fibrosis with eventual right ventricular overload and failure. In the current issue of the European Respiratory Journal, HofFMANN et al. [12] have employed supracoronary aortic banding in Sprague-Dawley rats as an experimental model for $\mathrm{PH}$ owing to left heart disease and monocrotaline (MCT) injection to create $\mathrm{PAH}$ and provide unique comparative insights into both pathological mechanisms. Whole rat genome microarray analyses of lungs from banded and control rats deliver novel gene expression information related to these two experimental conditions. Unfortunately, the venous and arterial compartments have not been separately investigated in these studies. Still, molecular analysis in combination with genetically modified Ws/Ws rats, which are deficient in mast cells, and a pharmacological approach by treatment of aortic banded rats with the mast cell stabiliser ketotifen have provided the simple concept that mast cells play a role in the pathogenesis of both disorders.

However, whether whole genome approaches that are based on the magnitude of the effect truly reflect biologically important mechanisms is uncertain. It is well-known that minor gene expression differences may implicate large biological effects. For example, a three base pair deletion within the cystic fibrosis transmembrane conductance regulator protein causes major disease [13]. Most prominently upregulated gene ontology clusters may reflect the presence of distinct cell populations, 
albeit without proving pathophysiological evidence for causality to a certain disorder. The authors were successful in providing evidence beyond the expression analysis by utilising Ws/Ws rats deficient in mast cells. Still, the proof of causality is not complete as mast cell activation is complex and could be secondary to another principle that is operative in both pre- and post-capillary $\mathrm{PH}$.

Mast cells release biogenic amines, including serotonin, which play a key role in pulmonary arterial vasoconstriction and smooth muscle cell proliferation [14], and histamine, which acts as a vasoconstrictor in pulmonary veins. In the circulation, thrombosis is driving mast cell accumulation [15]. However, HOFFMANN et al. [12] observed that vascular thrombosis was not common in lungs of MCT-treated rats or in those from rats with aortic banding. Mast cells were most prominently found in the vicinity of pulmonary arteries and arterioles, with the constraint that remodelled pulmonary veins may easily be misinterpreted as arteries. Capillary haemorrhage could be seen in some areas of lungs with $\mathrm{PH}$, yet did not co-localise with mast cell accumulations. However, visualisation of thrombosis in pathologic vascular specimens may be difficult because fresh thrombus is frequently fragile and disappears during tissue harvest due to unstable fibrin crosslinking [16]. Thus, mast cells may associate with fresh thrombus that escaped detection in the histological specimens, and the authors' finding may indirectly indicate the pathophysiological importance of small vessel thrombosis in both conditions.

Mast cells may be involved in a variety of adaptive or pathological responses associated with chronic inflammation and it has been demonstrated that mast cells contribute to bronchial or cardiac remodelling. Growth and function, i.e. mediator production and secretion of mast cells, are regulated by mast cell growth factor [17], also called stem cell factor or kit ligand [18]. This cytokine represents the ligand of the c-kit tyrosine kinase receptor clustered as CD117, a marker for bone marrow (BM)-derived haematopoietic stem cells and mast cells. Mast cells are increased in the lungs and remodelled vessels of experimental PH and human idiopathic PAH [19-21]. In idiopathic PAH, the accumulation of c-kit+ cells was associated with an increased expression of c-kit mRNA in microdissected pulmonary arteries and with an increase of soluble c-kit plasma levels compared to controls [22]. The involvement of lung mast cells has recently also been reported in animal models of hypoxic PH [23]. The implication of c-kit+ cells in the pathophysiology of $\mathrm{PH}$ may have clinical implications in the development of innovative therapy for this devastating disease. Tyrosine kinase inhibitors, such as imatinib, or combined tyrosine and multiple kinase inhibitors, such as sorafenib, improve experimental $\mathrm{PH}$ in animal models [24-26] and imatinib appeared favourable in human PAH [27]. A main effect of tyrosine kinase inhibitors appears to be related to the inhibition of the platelet-derived growth factor receptor that attenuates migration and proliferation, and enhanced apoptosis of pulmonary arterial smooth muscle cells. By reducing perivascular accumulation of c-kit+ cells, mainly BM-derived progenitor cells but also mast cells in pulmonary arteries of mice exposed to chronic hypoxia, imatinib improved pulmonary vascular remodelling [28, 29]. These data indicate that the beneficial effect of tyrosine kinase inhibitors in experimental or human PAH may be partly due to the inhibition of c-kit+ cells, which include mast cells.

HOFFMANN et al [12] augment this information, suggesting that mast cells are implicated in pulmonary vascular remodelling in experimental models of both $\mathrm{PAH}$ and $\mathrm{PH}$ due to left heart diseases. Thus, mast cells may provide the missing link between pre- and post-capillary $\mathrm{PH}$. Future experimental studies are needed to improve the understanding of mechanisms by which mast cells promote pulmonary vascular remodelling. Mast cell targeted therapy, including inhibition of the tyrosine kinase c-kit, may represent an innovative treatment in $\mathrm{PH}$, including the common variant of $\mathrm{PH}$ due to left heart disease.

\section{STATEMENT OF INTEREST}

Statements of interest for D. Montani and I.M. Lang can be found at www.erj.ersjournals.com/site/misc/statements.xhtml

\section{REFERENCES}

1 Galie N, Hoeper MM, Humbert M, et al. Guidelines for the diagnosis and treatment of pulmonary hypertension. Eur Respir J 2009; 34: 1219-1263.

2 Galie N, Hoeper MM, Humbert M, et al. Guidelines for the diagnosis and treatment of pulmonary hypertension. Eur Heart J 2009; 30: 2493-2537.

3 Lipman J. Pitfalls in the interpretation of pulmonary capillary wedge pressure. S Afr Med J 1985; 67: 174-177.

4 Tonelli AR, Mubarak KK, Li N, et al. Effect of balloon inflation volume on pulmonary artery occlusion pressure in patients with and without pulmonary hypertension. Chest 2011; 139: 115-121.

5 McLaughlin VV, Shillington A, Rich S. Survival in primary pulmonary hypertension: the impact of epoprostenol therapy. Circulation 2002; 106: 1477-1482.

6 Califf RM, Adams KF, McKenna WJ, et al. A randomized controlled trial of epoprostenol therapy for severe congestive heart failure: the Flolan International Randomized Survival Trial (FIRST). Am Heart J 1997; 134: 44-54.

7 Buchbinder N, Ganz W. Hemodynamic monitoring: invasive techniques. Anestesiology 1976; 45: 146-155.

8 Ghio S, Gavazzi A, Campana C, et al. Independent and additive prognostic value of right ventricular systolic function and pulmonary artery pressure in patients with chronic heart failure. J Am Coll Cardiol 2001; 37: 183-188.

9 Lam CS, Borlaug BA, Kane GC, et al. Age-associated increases in pulmonary artery systolic pressure in the general population. Circulation 2009; 119: 2663-2670.

10 Lam CS, Roger VL, Rodeheffer RJ, et al. Pulmonary hypertension in heart failure with preserved ejection fraction: a communitybased study. J Am Coll Cardiol 2009; 53: 1119-1126.

11 Kerem A, Yin J, Kaestle SM, et al. Lung endothelial dysfunction in congestive heart failure: role of impaired $\mathrm{Ca}^{2+}$ signaling and cytoskeletal reorganization. Circ Res 2010; 106: 1103-1116.

12 Hoffmann J, Yin J, Kukucka M, et al. Mast cells promote lung vascular remodelling in pulmonary hypertension. Eur Respir J 2011; 37: 1400-1410.

13 Riordan JR, Rommens JM, Kerem B, et al. Identification of the cystic fibrosis gene: cloning and characterization of complementary DNA. Science 1989; 245: 1066-1073.

14 MacLean MR, Dempsie Y. Serotonin and pulmonary hypertension - from bench to bedside? Curr Opin Pharmacol 2009; 9: 281-286.

15 Bankl HC, Radaszkiewicz T, Klappacher GW, et al. Increase and redistribution of cardiac mast cells in auricular thrombosis. Possible role of kit ligand. Circulation 1995; 91: 275-283.

16 Distelmaier K, Adlbrecht C, Jakowitsch J, et al. Local complement activation triggers neutrophil recruitment to the site of thrombus 
formation in acute myocardial infarction. Thromb Haemost 2009; 102: 564-572.

17 Zsebo KM, Williams DA, Geissler EN, et al. Stem cell factor is encoded at the $\mathrm{Sl}$ locus of the mouse and is the ligand for the c-kit tyrosine kinase receptor. Cell 1990; 63: 213-224.

18 Bischoff SC, Dahinden CA. c-Kit ligand: a unique potentiator of mediator release by human lung mast cells. J Exp Med 1992; 175: 237-244.

19 Heath D, Yacoub M. Lung mast cells in plexogenic pulmonary arteriopathy. J Clin Pathol 1991; 44: 1003-1006.

20 Davie NJ, Crossno JT Jr, Frid MG, et al. Hypoxia-induced pulmonary artery adventitial remodeling and neovascularization: contribution of progenitor cells. Am J Physiol Lung Cell Mol Physiol 2004; 286: L668-L678.

21 Crossno JT Jr, Garat CV, Reusch JE, et al. Rosiglitazone attenuates hypoxia-induced pulmonary arterial remodeling. Am J Physiol Lung Cell Mol Physiol 2007; 292: L885-L897.

22 Montani DPF, Perros F, Gambaryan N, et al. c-Kit positive cells accumulate in remodeled vessels of idiopathic pulmonary arterial hypertension. Am J Respir Crit Care Med 2011; [Epub ahead of print DOI: $10.1164 / \mathrm{rccm} .201006-200905 \mathrm{OC}$ ].

23 Banasova A, Maxova H, Hampl V, et al. Prevention of mast cell degranulation by disodium cromoglycate attenuates the development of hypoxic pulmonary hypertension in rats exposed to chronic hypoxia. Respiration 2008; 76: 102-107.

24 Schermuly RT, Dony E, Ghofrani HA, et al. Reversal of experimental pulmonary hypertension by PDGF inhibition. J Clin Invest 2005; 115: 2811-2821.

25 Klein M, Schermuly RT, Ellinghaus P, et al. Combined tyrosine and serine/threonine kinase inhibition by sorafenib prevents progression of experimental pulmonary hypertension and myocardial remodeling. Circulation 2008; 118: 2081-2090.

26 Moreno-Vinasco L, Gomberg-Maitland M, Maitland ML, et al. Genomic assessment of a multikinase inhibitor, sorafenib, in a rodent model of pulmonary hypertension. Physiol Genomics 2008; 33: 278-291

27 Ghofrani HA, Morrell NW, Hoeper MM, et al. Imatinib in pulmonary arterial hypertension patients with inadequate response to established therapy. Am J Respir Crit Care Med 2010; 182: 1171-1177.

28 Gambaryan N, Perros F, Montani D, et al. Imatinib inhibits bone marrow-derived c-kit+ cell mobilisation in hypoxic pulmonary hypertension. Eur Respir J 2010; 36: 1209-1211.

29 Gambaryan N, Perros F, Montani D, et al. Targeting of c-kit+ hematopoietic progenitor cells prevents hypoxic pulmonary hypertension. Eur Respir J 2010; [Epub ahead of print DOI: 10.1183/09031936.00045710]. 